How to cite: Özkaynak, E.Ş̧imşek, T., Determination of Drought Tolerance on Advanced Potato Lines In Vitro Conditions, Ege Univ. Ziraat Fak. Derg., 2018, 55 (2):237-243, DOI:10.20289/zfdergi.340661

Araştırma Makalesi (Research Article)

Ercan ÖZKAYNAK

Tuğba ŞIMŞEK

Yüksel Tohum Tarım San. Ve Tic. A. Ş. Antalya/Türkiye, sorumlu yazar: eozkaynak@yukseltohum.com

Anahtar Sözcükler:

Illeri hat, Islah, kuraklık, patates, PEG 6000

Key Words:

Advanced line, breeding, drought, potato, PEG 6000
Ege Üniv. Ziraat Fak. Derg., 2018, 55 (2):237-243

DOI: $10.20289 /$ zfdergi.340661

\section{Illeri Patates Hatlarının Kuraklık Toleransının In Vitro Koşullarda Belirlenmesi}

\author{
Determination of Drought Tolerance on Advanced Potato Lines \\ In Vitro Conditions
}

Alınış (Received): 29.09.2017 Kabul tarihi (Accepted): 15.02.2018

\begin{abstract}
ÖZET
$\Delta$ raştırma bazı ileri patates hatlarında in vitro koşullarda PEG 6000 kullanılarak Aoluşturulan kuraklık stresinin etkisini belirlemek amacıyla yapılmıștır. Araştırma doku kültürü laboratuvarında 2016 yılı Ocak - Mayıs ayları arasında gerçekleștirilmiştir. Araştırma tesadüf parsellerinde bölünmüş parseller deneme desenine göre; MS0: PEG yok, P1: \%3 PEG, P2= \%10 PEG ve P3=\%15 PEG olarak adlandırılan 4 PEG konsantrasyonu kullanılarak 3 tekerrürlü olarak yapılmıştır. Bitki boyu, bitki başına boğum sayısı ve bitki yaş ağırlığı gibi bitki özellikleri 20 ve 40 günlük kültür periyotlarında ölçülmüş ve değerlendirilmiştir. Genel olarak P1 (MS + \%3 sukroz $+7 \mathrm{~g} / \mathrm{lagar}+\% 3 \mathrm{PEG})$, P2 (MS + \%3 sukroz $+7 \mathrm{~g} / \mathrm{lagar}+\% 10$ PEG) ve P3 (MS + \%3 sukroz + $7 \mathrm{~g} / \mathrm{l}$ agar + \%15 PEG) ortamlarına göre tüm bitki özelliklerinde en yüksek değerler MSO (MS + \%3 sukroz + $7 \mathrm{~g} / \mathrm{l}$ agar ) ortamında elde edilmiştir. Araştırma sonuçlarına göre PEG konsantrasyonu arttıkça bitki boyu, bitki başına boğum sayısı, bitki yaş ağırlığı ve bitki büyüme ve gelişmesi azalma göstermiştir. Araştırma sonucuna göre 13-80-44 ve 22-99-33 ileri hatları PEG 6000 içeren in vitro koşullarda kuraklık toleranslı hatlar olarak seçilmiştir.
\end{abstract}

\begin{abstract}
his study aim was to determine the effect of some advanced potato lines to drought stress conditions in vitro using PEG 6000 . This research was conducted at the Tissue Culture Laboratory in January 2016 to May 2016. The Randomized Split Block Design was carried out PEG concentrations of three levels, namely: MS0: no PEG, P1: 3\% PEG, P2= 10\% PEG and P3: 15\% PEG with three replications. Plant traits such as plant height, number of nodes per plant and plant fresh weight were measured and evaluated after 20 and $\mathbf{4 0}$ days of culture period. In general, the higher values were obtained from MSO (MS + 3\% sucrose $+7 \mathrm{~g} / \mathrm{l}$ agar ) compare to P1 (MS + 3\% sucrose $+7 \mathrm{~g} / \mathrm{lagar}+3 \% \mathrm{PEG}), \mathrm{P2}$ (MS $+3 \%$ sucrose $+7 \mathrm{~g} / \mathrm{lagar}+10 \% \mathrm{PEG}$ ) and P3 (MS + $3 \%$ sucrose $+7 \mathrm{~g} / \mathrm{lagar}+$ $15 \%$ PEG) for all plant characteristics. The research results showed that increasing the concentration of PEG will reduce plant height, number of nodes per plant, plant fresh weight and plant growth and development. As a result of the research, 13-80-44 and 22-99-33 advanced lines were selected as drought tolerant lines in vitro PEG 6000 induced conditions.
\end{abstract}

\section{Giriş}

Bitkiler doğal koşullarda büyürken kuraklık, düşük ve yüksek sıcaklık, tuzluluk, sel, oksidatif stres ve ağır metal toksitetesi gibi birçok abiyotik stres faktörleri ile karşı karşıya gelmektedir (Mengü-Pamuk ve ark. 2011). Genellikle kuraklık stresi topraktaki kullanışlı su azaldığında ve atmosferik koşullar sürekli olarak buharlaşma ve terleme ile su kaybına neden olduğunda ortaya çıkmaktadır. Patates yağmurla beslenen ya da sulu koşullarda diğer önemli kültür bitkilere göre birim su başına elde edilen ürün bakımından daha yüksek verime sahiptir Uygulanan her $\mathrm{m}^{3}$ su başına patates 5600 kcal enerji üretirken, bu değerler mısırda 3860 kcal, buğdayda 2300 kcal ve çeltikte 2000 kcal olarak belirtilmiştir (Renault and Wallender, 2000; Monneveux et al. 2013). Patates kuraklığa oldukça hassas bir bitki olmasına rağmen bazı morfolojik ve fizyolojik tepkiler verebilmektedir (Yuan et al. 2003; Schafleitner et al. 2007; Stark et al. 2013; Soltys-Kalina et al. 2016). Yine de belirli bir süre su stresine maruz kaldığında kuraklık 
etkisini hemen göstermekte ve yüzeysel kök gelişimi ve üretimde kapasite düşüklüğü meydana gelmektedir (Iwama and Yamaguchi, 2006).

Patateste kuraklık bitki büyümesini azaltmakta (Deblonde and Ledent, 2001), büyüme süresini kısaltmakta (Kumar et al. 2007) ve yumru büyüklüğünü ve sayısını azaltmakta (Eiasu et al. 2007; Schafleitner et al. 2007; Monneveux et al. 2013) tarla koşullarında kuraklık yumru verim ve kalitesinde önemli azalmalara neden olmaktadır (Lahlou et al. 2003, Stark et al. 2013). Kuraklığa toleranslı patates çeşitleri geliştirmek için klasik olarak tarla koşullarında moleküler ve fizyolojik seviyede tolerant çeşitleri belirlemek için farklı teknikler kullanılmaktadır. Klasik olarak tarla koşullarında kuraklık toleransını belirlemek yerine in vitro koşullarda seleksiyon, stres faktörlerine toleranslı hatların geliştirilmesi için son zamanlarda alternatif ve kolay bir yöntem olarak uygulama alanı bulmaktadır (Monneveux et al. 2013). In vitro koşullarda su stresi etkisinin tarla koşullarındaki etkiye benzer özellikler gösterdiği ve in vitro koşullarda da tarla koşullarına benzer şekilde su stresinde; büyümede gerileme, ağırlık kaybı, kök sayısı ve kök kuru ağırlığında azalma görüldüğü belirtilmiştir (Gopal and Iwama, 2007; Monneveux et al. 2013).

Patateste in vitro kültür teknikleri belirli koşullarda ve içeriği bilinen bir besin ortamında uygulandığı için çevresel değişimler minimum düzeyde kontrol edilebilmekte ve homojen bir ortam sağlanabilmektedir (Manoj and Uday, 2007; Monneveux et al. 2013). Polietilen glikol (PEG), yüksek moleküler ağırlığa sahip (1500-8000 arasında değişen moleküler ağırlıkları mevcuttur), suda çözünebilen ve bitkiler için toksik olmayan bir polimerdir. Yüksek moleküler ağırlığından dolayı köklerde ve sürgünlerde alınma oranı oldukça yavaştır ve bitki türlerine, konsantrasyonuna ve uygulama zamanına göre değişmektedir (Yaniv ve Werker, 1983; Jacomini et al. 1988). Bu özelliğinden dolayı bitkilerde suni kuraklık etkisi yaratmak amacıyla kullanılmaktadır (Tabori et al. 2017). PEG ile kuru (susuz) topraktaki düşük su potansiyeline benzer koşullar suni olarak sağlanabilmekte ve fide aşamasında bitkilerde kök ve sürgün gelişmesi incelenebilmektedir (Nistor et al. 2014).

Araştırma patateste üstün özelliklere sahip çeşit adayı ileri ıslah hatları ve bazı çeşitlerin in vitro koşullarda polietilen glikol içeren besin ortamında su stresine ve dolayısıyla da kuraklığa tolerans seviyesini belirlemek amacıyla yürütülmüşsür.

\section{MATERYAL ve YÖNTEM}

Araştırma kapsamında 2008-2016 tarihleri arasında patateste Türkiye koşullarına uygun erkenci yemeklik patates çeşitleri geliştirmek amacıyla ıslah çalışmaları yürütülmüştür. Islah çalışmaları sonucunda bitki, yumru, verim ve kalite özellikleri yönünden üstün özellik gösteren 6 ileri patates hattı seçilmiştir. 6 ileri patates hattı (11-03-38 (orta erkenci), 12-55-07 (erkenci-orta erkenci), 12-69-39 (orta erkenci), 12-85-11 (orta erkenci), 22-99-33 (orta erkenci-geçci) ve 13-80-44 (orta erkencigeçci ) ve 2 patates çeşidi (Milva (orta erkenci) ve Saline (orta erkenci) araştırmada bitki materyal olarak kullanıımıştır. In vitro koşullarda geliştirilmiş ileri patates hatları ve çeşitlerine ait stok bitkilerden alınan tek boğum eksplantları \%3 sukroz, 7g/1 agar içeren MS (Murashige and Skoog, 1962) besin ortamında petri kutularında 2 hafta süreyle geliştirilmiştir. Gelişmiş patates hat ve çeşitlerine ait bitkilerden alınan tek boğum eksplantları araştırmada kullanılmıştır. Araştırmada MS besin ortamı kullanıımış ve çalışma petri kutusunda yapılmıştır.

Patates hatları ve çeşitleri 4 farklı besin ortamında büyütülmüştür. Besin ortamına ilave edilen PEG 6000 ile kuraklık stresi oluşturulmuştur. Araştırmada ilk ortam olarak, $\% 3$ sukroz $+7 \mathrm{~g} / 1$ agar içeren MSO besin ortamı, ikinci ortam olarak \%3 sukroz $+7 \mathrm{~g} / 1$ agar $+\% 3$ PEG içeren P1 ortamı, üçüncü ortam olarak $\% 3$ sukroz $+7 \mathrm{~g} / 1$ agar $+\% 10$ PEG içeren P2 ortamı ve dördüncü ortam olarak \%3 sukroz $+7 \mathrm{~g} / 1$ agar $+\% 15$ PEG içeren P3 ortamı kullanılmıştır. Besin ortamlarının pH'sı 5.7'ye ayarlandıktan sonra $121^{\circ} \mathrm{C}^{\prime}$ de 20 dakika süreyle otoklav edilmiştir. Kültürler 16 saat ışık 8 saat karanlık ortamda ve $25 \pm 2{ }^{\circ} \mathrm{C}$ sıcaklıkta büyütülmüşlerdir. Araştırmada her petri kutusuna $5^{\prime}$ er adet tek boğum içeren eksplant konulmuştur. Araştırmada her çeşit ve hat için her ortamda 12'şer petri kutusu kullanılmıştır. Araştırmada 20 ve 40 günlük kültür süresinde bitki kök, yaprak ve gövde gelişimi in vitro koşullarda bitki gelişimi olarak değerlendirilmiş, ayrıca bitki boyu, boğum sayısı, bitki yaş ağırlığı özellikleri ölçülmüştür. Bitki yaş ağırlığı, boğum sayısı ve bitki boyu değerleri 5 'er bitki kullanılarak saptanmıştır. Araştırma 2 kez tekrar edilerek elde edilen verilerin ortalaması değerlendirmeye alınmıştır. 20 günlük ilk kültür süresinden sonra bitkilerde steril kabin içinde gerekli ölçümler yapılarak aynı bitkiler tekrar aynı oranlarda PEG içeren yeni besin ortamlarına konulmuş ve 40 gün süresince büyüme ve gelişmeye devam etmişlerdir. Bitkinin genel yapısı (kök, yaprak ve gövde gelişimine göre) 1-5 skalası kullanılarak değerlendirilmiştir (Bhattarai, 2017). 1-5 skala değerlendirmesi; 1: çok az gelişme, 2: az gelişme, 3: orta düzeyde gelişme 4: iyi gelişme ve 5: çok iyi büyüme ve gelişme, olarak yapılmıştır. Araştırmada elde edilen veriler tesadüf parsellerinde bölünmüş parseller deneme desenine göre MSTAT-C istatistik programı (Freed et al. 1989) kullanılarak varyans analizine tabi tutulmuş, ortalama değerler LSD testi (istatistik olarak 0.01 önem seviyesinde) ile değerlendirilmiştir 


\section{ARAŞTIRMA BULGULARI}

Araştırmada ilk 20 günde ve toplamda 40 günde tüm çeşit ve ileri hatlarda en iyi bitki büyüme ve gelişmesi MSO ortamında gözlenmiştir (Çizelge 1). 20 günlük kültür süresinde 22-99-33 ve 13-80-44 hatları ve Milva çeşidi bitki gelişimi bakımından iyi performans göstermiştir. 40 günlük kültür süresi sonunda ise 12-6929, 22-99-33, 13-80-44 hatları ve Milva çeşidi alt kültüre alınabilecek ve in vitro çoğaltım yapılabilecek seviyede bitki gelişimi sağlamışlardır. Saline çeşidi ve diğer hatlar ise daha zayıf bitki gelişimi göstermişlerdir. \%10 PEG içeren ortamda Milva çeşidi ve 13-80-44 hattı orta düzeyde büyüme ve gelişme göstermiş diğer çeşitlerde gelişmede gerileme görülmüştür. \%15 PEG ortamında ise 13-80-44 hattında daha az olmak üzere tüm çeşitlerde büyüme ve gelişme gerilemiştir.

Araştırmada bitki boyu, boğum sayısı ve bitki yaş ağırlığı özellikleri yönünden kültür süreleri, PEG besin ortamları ve çeşit-hatlar arasında istatistiksel olarak önemli farklıııklar bulunmuştur.
Araştırmada bitki boyu değerleri tüm çeşit ve hatlarda kültür süresi 20 günden 40 güne devam ettikçe 4 ortamda da artış göstermiş̧ir. Bitki boyu değerleri MSO ortamında yüksek bulunurken, PEG içeren $P 1, P 2$ ve $P 3$ ortamlarında daha düşük bulunmuştur (Çizelge 2). \%10 PEG içeren ortam bitki gelişimini ve bitki boyu uzamasını olumsuz yönde etkilemiş, \%15 PEG içeren ortamda ise bitkilerde büyüme durma noktasına gelmiş ve çok az gelişme gözlenmiştir. Bitki boyu bakımından 40 günlük kültür süresi sonunda en yüksek değerler MSO ortamında $7.48 \mathrm{~cm}$ ve $7.35 \mathrm{~cm}$ ile Milva ve Saline çeşitlerinde bulunmuş bu çeşitleri 13-80-44, 12-55-07 ve 22-99-33 hatları izlemiştir. P1, P2 ve P3 ortamlarının genel çeşitler ortalaması olarak en yüksek değerler 4.53 $\mathrm{cm}$ ile Milva, $3.89 \mathrm{~cm}$ ile 13-80-44 ve $3.51 \mathrm{~cm}$ ile Saline çeşitlerinde elde edilmiştir. 20 ve 40 günlük kültür sürelerinde PEG içeren ortamlarda ise en yüksek değerler Milva, Saline, çeşitleri ve 13-80-44 hattında elde edilmiştir. PEG konstrasyonu artıkça PEG suni kuraklık etkisinden dolayı bitki boyu değerleri azalmış ve yapraklarda küçülme görülmüştür.

Çizelge 1. Patateste in vitro koşullarda PEG içeren besin ortamında bitki gelişimi

Table 1. Plant development of in vitro conditions in PEG including medium in potato

\begin{tabular}{|l|c|c|c|c|c|c|c|c|}
\hline \multirow{2}{*}{ Çeşitler / Hatlar } & \multicolumn{9}{|c|}{ Bitki Gelişimi } \\
\cline { 2 - 10 } & \multicolumn{9}{|c|}{ 20 gün } & \multicolumn{5}{c|}{} \\
\cline { 2 - 9 } & MS0 & P1 (\%3 PEG) & P2 (\%10 PEG) & P3 (\%15 PEG) & MS0 & P1 (\%3 PEG) & P2 (\%10 PEG) & P3 (\%15 PEG) \\
\hline $11-03-38$ & 5 & 4 & 2 & 1 & 5 & 4 & 2 & 1 \\
\hline $12-55-07$ & 5 & 3 & 2 & 1 & 5 & 4 & 2 & 1 \\
\hline $12-69-39$ & 5 & 2 & 1 & 1 & 5 & 3 & 2 & 1 \\
\hline $12-85-11$ & 5 & 2 & 1 & 1 & 5 & 3 & 1 & 1 \\
\hline $22-99-33$ & 5 & 3 & 3 & 2 & 5 & 4 & 2 & 1 \\
\hline $13-80-44$ & 5 & 3 & 3 & 2 & 5 & 4 & 3 & 2 \\
\hline Saline & 5 & 3 & 2 & 1 & 5 & 3 & 2 & 1 \\
\hline Milva & 5 & 4 & 3 & 2 & 5 & 4 & 3 & 2 \\
\hline
\end{tabular}

Çizelge 2. Patateste in vitro koşullarda PEG içeren besin ortamında bitki boyu

Table 2. Plant height of in vitro conditions in PEG including medium in potato

\begin{tabular}{|c|c|c|c|c|c|c|c|c|c|c|}
\hline \multirow[b]{3}{*}{ Çeşitler / Hatlar } & \multicolumn{10}{|c|}{ Bitki Boyu $(\mathrm{cm})$} \\
\hline & \multicolumn{5}{|c|}{20 gün } & \multicolumn{5}{|c|}{40 gün } \\
\hline & MSO & $\begin{array}{c}\text { P1 (\%3 } \\
\text { PEG) }\end{array}$ & $\begin{array}{c}\text { P2 (\%10 } \\
\text { PEG) }\end{array}$ & $\begin{array}{c}\text { P3 (\%15 } \\
\text { PEG) }\end{array}$ & $\begin{array}{c}\text { PEG* } \\
\text { Çeşit/Hat } \\
\text { Ortalama }\end{array}$ & MSO & $\begin{array}{c}\text { P1 (\%3 } \\
\text { PEG) }\end{array}$ & $\begin{array}{c}\text { P2 (\%10 } \\
\text { PEG) }\end{array}$ & $\begin{array}{c}\text { P3 (\%15 } \\
\text { PEG) }\end{array}$ & $\begin{array}{c}\text { PEG } \\
\text { Çeşit/Hat } \\
\text { Ortalama }\end{array}$ \\
\hline $11-03-38$ & 3.34 & 3.92 & 2.41 & 2.0 & $2.78 \mathrm{c}$ & 4.08 & 3.98 & 2.98 & 2.20 & $3.05 d$ \\
\hline $12-55-07$ & 4.22 & 2.75 & 2.13 & 1.87 & $2.25 \mathrm{~d}$ & 6.79 & 4.52 & 2.62 & 1.89 & $3.01 \mathrm{~d}$ \\
\hline $12-69-39$ & 5.18 & 2.28 & 1.81 & 1.60 & 1.90de & 6.62 & 4.64 & 2.74 & 1.78 & $3.05 d$ \\
\hline $12-85-11$ & 4.88 & 3.45 & 2.45 & 2.10 & $2.67 c d$ & 6.52 & 3.68 & 2.64 & 2.20 & 2.84de \\
\hline $22-99-33$ & 6.12 & 3.28 & 2.82 & 2.30 & $2.80 c$ & 6.69 & 3.64 & 2.98 & 2.44 & $3.02 d$ \\
\hline $13-80-44$ & 6.10 & 3.79 & 3.25 & 2.90 & $3.31 b$ & 6.91 & 5.20 & 3.52 & 2.95 & $3.89 \mathrm{~b}$ \\
\hline Saline & 5.32 & 3.64 & 2.78 & 2.20 & $2.87 c$ & 7.48 & 5.20 & 2.92 & 2.40 & $3.51 \mathrm{c}$ \\
\hline Milva & 5.78 & 4.51 & 4.51 & 3.20 & $4.07 a$ & 7.35 & 5.58 & 4.61 & 3.40 & $4.53 a$ \\
\hline Ortalama & 5.12 & 3.46 & 2.77 & 2.28 & 2.84 & 6.56 & 4.56 & 3.13 & 2.41 & 3.36 \\
\hline \multicolumn{6}{|l|}{ CV: \%10.93 } & \multicolumn{5}{|c|}{ LSD 0.01: 0.30} \\
\hline
\end{tabular}

*PEG Çeşit/Hat Ortalması P1, P2 ve P3 uygulamaları ortalaması olarak hesaplanmıştır. 
Bitki başına boğum sayısı patateste in vitro çoğaltımda en önemli bitki özelliklerinden biridir (Gopal, 2001). Boğum sayısı artıkça bitki başına elde edilebilecek eksplant sayısı dolayısıyla da sonraki aşamada üretilebilecek bitki sayısı artış gösterecektir. 20 ve 40 günlük kültür süresinde çeşitlerde ve hatlarda PEG oranı artıkça elde edilen boğum sayısında azalma görülmüştür (Çizelge 3). Ortalama boğum sayısı değerleri MSO ortamında 40 gün süresi sonunda 26.73 adet iken; P1 oramında 18.24 adet, P2 ortamında 13.51 adet ve $\mathrm{P} 3$ ortamında 9.42 adet olarak bulunmuştur. 20 günlük kültür süresinde bitki boyu değerleri MSO ortamında en az 14.34 adet ile Saline çeşidinde bulunurken, en yüksek değer 27.20 adet ile 22-99-33 hattında elde edilmiştir. 20 günlük kültür süresinde P1 ortamında 13-80-44 ve 22-99-33 hatları, P2 ortamında 12-55-07, 13-80-44 hatları ve Milva çeşidi, P3 ortamında ise 11 adet ile 12-55-07 hattı en yüksek değerleri vermiş̧ir. 40 günlük kültür süresinde en yüksek boğum sayısı 32.1 adet 12-85-11 hattında MSO ortamında bulunmuş, en düşük boğum sayısı değeri ise 6.5 adet ile Saline çeşidinde \%15 PEG içeren P3 ortamında elde edilmiştir. Genel olarak çeşitler arasında Milva çeşidi, hatlar arasında ise 12-55-07, 13-80-44 ve 22-99-33 hatları kuraklık tolerasında iyi performans göstermişler ve bitki başına fazla sayıda boğum oluşturmuşlardır.

Bitki yaş ağırlığı bakımından her iki kültür süresinde de MSO ortamı yüksek değerler oluşturmuştur. PEG oranı artıkça bitki yaş ağırlığı değerleri düşüş göstermiştir (Çizelge 4).

Çizelge 3. Patateste in vitro koşullarda PEG içeren besin ortamında bitki başına boğum sayısı

Table 3. Number of stem per plant in vitro conditions in PEG including medium in potato

\begin{tabular}{|c|c|c|c|c|c|c|c|c|c|c|}
\hline \multirow[b]{3}{*}{ Çeşitler / Hatlar } & \multicolumn{10}{|c|}{ Bitki Başına Boğum Sayısı (adet) } \\
\hline & \multicolumn{5}{|c|}{20 gün } & \multicolumn{5}{|c|}{40 gün } \\
\hline & MSO & $\begin{array}{c}\text { P1 (\%3 } \\
\text { PEG) }\end{array}$ & $\begin{array}{c}\text { P2 (\%10 } \\
\text { PEG) }\end{array}$ & $\begin{array}{c}\text { P3 (\%15 } \\
\text { PEG) }\end{array}$ & $\begin{array}{c}\text { PEG* } \\
\text { Çeşit/Hat } \\
\text { Ortalama }\end{array}$ & MSO & $\begin{array}{c}\text { P1 (\%3 } \\
\text { PEG) }\end{array}$ & $\begin{array}{l}\text { P2 (\%10 } \\
\text { PEG) }\end{array}$ & $\begin{array}{c}\text { P3 (\%15 } \\
\text { PEG) }\end{array}$ & $\begin{array}{c}\text { PEG } \\
\text { Çeşit/Hat } \\
\text { Ortalama }\end{array}$ \\
\hline $11-03-38$ & 20.20 & 12.69 & 9.10 & 7.0 & $9.6 \mathrm{e}$ & 22.10 & 13.34 & 10.10 & 7.20 & 10.21de \\
\hline $12-55-07$ & 21.10 & 15.35 & 14.20 & 11.0 & $13.52 \mathrm{~b}$ & 31.68 & 21.34 & 18.34 & 11.10 & $16.93 a$ \\
\hline $12-69-39$ & 15.69 & 12.10 & 10.20 & 9.0 & $10.47 \mathrm{~cd}$ & 26.10 & 13.35 & 11.34 & 9.20 & $11.30 \mathrm{~d}$ \\
\hline $12-85-11$ & 26.33 & 16.34 & 12.10 & 9.50 & $12.65 \mathrm{C}$ & 32.10 & 17.68 & 14.68 & 9.50 & $13.95 \mathrm{c}$ \\
\hline $22-99-33$ & 27.20 & 22.20 & 12.10 & 10.0 & 14.77ab & 29.34 & 22.69 & 12.69 & 10.20 & $15.19 b$ \\
\hline $13-80-44$ & 25.34 & 23.35 & 13.10 & 10.60 & $15.68 \mathrm{a}$ & 30.69 & 25.20 & 15.34 & 10.70 & $17.08 \mathrm{a}$ \\
\hline Saline & 14.34 & 13.34 & 8.68 & 6.50 & $9.51 \mathrm{e}$ & 16.10 & 15.10 & 9.34 & 6.50 & 10.31de \\
\hline Milva & 18.68 & 15.34 & 13.34 & 10.80 & $13.16 \mathrm{bc}$ & 25.68 & 17.20 & 16.20 & 10.9 & $14.77 \mathrm{bc}$ \\
\hline Ortalama & 21.11 & 16.34 & 11.61 & 9.30 & 12.42 & 26.73 & 18.24 & 13.51 & 9.42 & 13.72 \\
\hline \multicolumn{6}{|l|}{ CV:\%12.89 } & \multicolumn{5}{|c|}{ LSD 0.01: 1.83} \\
\hline
\end{tabular}

*PEG Çeşit/Hat Ortalması P1, P2 ve P3 uygulamaları ortalaması olarak hesaplanmıştır.

Çizelge 4. Patateste in vitro koşullarda PEG içeren besin ortamında bitki yaş ağırlığı

Table 4. Plant fresh weight in vitro conditions in PEG including medium in potato

\begin{tabular}{|c|c|c|c|c|c|c|c|c|c|c|}
\hline \multirow[b]{3}{*}{ Çeşitler / Hatlar } & \multicolumn{10}{|c|}{ Bitki Yaş Ağırlığı (mg) } \\
\hline & \multicolumn{5}{|c|}{20 gün } & \multicolumn{5}{|c|}{40 gün } \\
\hline & MSO & \begin{tabular}{|l|} 
P1 (\%3 \\
PEG)
\end{tabular} & $\begin{array}{l}\text { P2 (\%10 } \\
\text { PEG) }\end{array}$ & $\begin{array}{l}\text { P3 (\%15 } \\
\text { PEG) }\end{array}$ & \begin{tabular}{|l|} 
PEG* \\
Çeşit/Hat \\
Ortalama \\
\end{tabular} & MSO & \begin{tabular}{|l} 
P1 (\%3 \\
PEG)
\end{tabular} & \begin{tabular}{|l|} 
P2 (\%10 \\
PEG)
\end{tabular} & \begin{tabular}{|l} 
P3 (\%15 \\
PEG)
\end{tabular} & \begin{tabular}{|l|} 
PEG \\
Çeşit/Hat \\
Ortalama \\
\end{tabular} \\
\hline $11-03-38$ & 152 & 102 & 42 & 20 & $54.67 d$ & 182 & 173 & 112 & 21 & $102 \mathrm{bc}$ \\
\hline $12-55-07$ & 181 & 172 & 92 & 60 & 108ab & 283 & 263 & 172 & 61 & 165.33ab \\
\hline $12-69-39$ & 142 & 102 & 82 & 56 & $80 \mathrm{bc}$ & 273 & 242 & 202 & 57 & $167 a b$ \\
\hline $12-85-11$ & 202 & 122 & 102 & 70 & $98 b$ & 292 & 202 & 131 & 71 & $134.67 \mathrm{~b}$ \\
\hline $22-99-33$ & 313 & 122 & 53 & 24 & 66.33 & 353 & 183 & 122 & 25 & $110 \mathrm{bc}$ \\
\hline $13-80-44$ & 214 & 203 & 172 & 86 & $153.67 a$ & 343 & 243 & 202 & 87 & $177.33 a$ \\
\hline Saline & 132 & 92 & 82 & 54 & $76 \mathrm{bc}$ & 202 & 144 & 112 & 55 & $103.67 \mathrm{bc}$ \\
\hline Milva & 202 & 131 & 101 & 70 & $100.67 \mathrm{~b}$ & 232 & 173 & 132 & 71 & $125.33 b$ \\
\hline Ortalama & 192.25 & 130.75 & 90.75 & 55 & 92.17 & 270 & 202.88 & 148.13 & 56 & 135.67 \\
\hline \multicolumn{6}{|l|}{ CV: \%13.83 } & \multicolumn{5}{|c|}{ LSD 0.01: 79} \\
\hline
\end{tabular}

*PEG Çeşit/Hat Ortalması P1, P2 ve P3 uygulamaları ortalaması olarak hesaplanmıştır

MSO ortamında 20 günde ortalama olarak 192.25 mg yaş ağırlık bulunurken 40 günde bu değer $270 \mathrm{mg}$ olarak elde edilmiştir. P1 ortamında yaş ağırlık değeri ise 20 günde $130.75 \mathrm{mg}$ iken 40 gün sonunda ortalama 202.88 mg olarak gerçekleşmiştir. \%10 PEG içeren P2 ortamında ise bitki yaş ağırlığı değerleri 90.75 mg'dan 40 gün sonunda 148.13 mg'a yükselmiştir. \% 15 PEG içeren P3 ortamında bitki yaş ağırlığı değerleri ortalaması çok az değişim göstererek ortalama olarak 55 mg'dan 56 mg'a yükselmiştir. Çeşit ve hatlar arasında 
20 günlük kültür süresi sonunda kuraklık tolerası en iyi hat (besin ortamlarında sırasıyla 214 mg, 203 mg, 172 $\mathrm{mg}$ ve $86 \mathrm{mg}$ ve ortalama $153.67 \mathrm{mg}$ ağırlık değerler ile) 13-80-44 hattı olarak belirlenmiştir. 40 günlük kültür süresinde 13-80-44 hattı, 12-55-07 ve 12-69-39 hatları üstün performans göstermiştir. Diğer hat ve çeşitlerde yaş ağırlık değerleri özellikle \%15 PEG içeren P3 ortamında diğer üç ortama göre çok daha fazla düşüş göstermiştir.

\section{TARTIŞMA}

Araştırma in vitro koşullarda PEG 6000 ile sağlanan suni kuraklık stresi uygulamasının patates çeşit ve hatlarının gelişimine etkilerini belirlemek ve kuraklığa tolerant çeşit ve hatları belirlemek amacıyla yürütülmüştür. Araştırmada 4 farklı ortam kullanılmış, 20 ve 40 günlük kültür süresince bitkilerin gelişim durumları değerlendirilmiştir. PEG içermeyen MSO ortamında bitki boyu, bitki başına boğum sayısı, bitki yaş ağırlığı ve genel olarak bitki gelişimi indeksi \%3 PEG ve \%10 PEG içeren suni kuraklık stres ortamlarına göre daha yüksek değerler vermiştir. \%15 PEG içeren ortam ise sert bir kuraklık etkisi yaratarak gelişmeyi olumsuz yönde etkilemiştir.

Kuraklığın mitoz bölünmeyi, hücre uzamasını ve büyümesini engelleyerek bitki boyu, yaprak alanı ve bitki büyümesinde azalamaya neden olduğu belirtilmiştir (Kaya ve ark. 2006; Hussain et al. 2008). Kuraklığın, patateste yaprak sayısı, yaprak alanı, sap sayısı, yumru sayısı ve yumru veriminde azalmalara neden olduğu bildirilmiştir (Schittenhelm et al. 2006; Albiski et al. 2013). Charloq et al. (2012) in vitro koşullarda patateste PEG konsantrasyonu artıkça bitkilerde yaşama oranının düştüğünü, bitki boyu, kök ve boğum sayısının azaldığını belirtmişlerdir. Yaptığımız araştırmada da in vitro koşullarda kuraklık stres koşullarında PEG içeren ortamlarda benzer şekilde bitki boyu ve boğum sayısı azalmış ve bitki büyümesinde gerileme saptanmıştır. Yine suni kuraklık etkisiyle fotosentez oranının düşmesi ve büyümenin gerilemesi sonucunda yaprak gelişimi ve yaprak büyüklüğünde küçülme ve daralma görülmüştür.

Patateste kuraklığın vejatatif büyümeyi, sürgün büyümesini, yaprak büyüklüğünü ve sayısını azalttığı belirtilmiştir (Weisz et al. 1994; Deblonde and Ledent, 2001). Buna ek olarak kuraklık stresinin patateste stomaların kapanmasına neden olarak gaz alış-verişini azalttığı ve terleme ve fotosentez oranında azalmalara neden olduğu bildirilmiştir (Ekanayake and Midmore, 1992; Dalla Costa et al. 1997; Deblonde and Ledent, 2001; Kızıloğlu ve ark. 2006; Pino et al. 2013). Buna rağmen patates bitkilerinin yumrularda daha yüksek asimilasyon oranı ile daha büyük yumru ya da daha fazla sayıda yumru oluşumu sağlayarak çeşitli yollarla kuraklık stresine toleransını artırabildiği belirtilmiştir (Deblonde and Ledent, 2001; Soltys-Kalina et al. 2016). Araşsırmada kültür süresi 20 günden $40^{\prime}$ güne çıktıkça genel olarak bitki büyümesi az da olsa devam etmesine rağmen, MS0 ortamına göre $\% 3$ ve $\% 10$ PEG içeren ortamlarında suni kuraklık stresi etkisiyle boğum sayısı, bitki boyu ve bitki yaş ağırlığında düşme, yapraklarda küçülme, boğum arasında daralma ve gelişmede yavaşlama görülmüştür. Özellikle de \%15 PEG içeren ortamda etki çok daha yoğun görülmüştür ve gelişme çok çok yavaşlamıştır.

Quayyum and Shoaib (2013), Cardinal patates çeşidinde MS ortamında \%5, \%10 ve \%20 PEG 6000 ilavesinde bitkilerin kuraklık tepkisini 4 hafta süreyle araştırmışlardır. Sürgün uzunluğu ve bitki yaş ağırlığında PEG konsantrasyonu artıkça azalma gözlemlenmiştir. Nistor et al. (2014), 6 patates çeşidinde in vitro koşullarda suni kuraklık stresinin etkilerini araştırdıkları çalışmalarında MS ortamına ilave edilen \%4.8 ve \%9.6 konsantrasyonlarındaki PEG uygulamalarının bitki gelişimine etkilerini belirledikleri çalışmalarında 6 haftalık gelişme süresi sonunda yaprak sayısı, bitki boyu ve yaş ağırlık gibi özelliklerdeki değişimler analiz edilmiştir. Araşsırmada PEG konsantrasyonu artıkça bitki büyümesinde azalma görülmüş ve çeşitler arasında kuraklığa tepki yönünden farklılıklar saptanmıştır. Araştırmada PEG 6000'in in vitro koşullarda su stres ajanı olarak kullanılabileceği sonucuna varılmış ve iki çeşit kuraklığa tolerant çeşit olarak değerlendirilmiştir. Deng et al. (2014), Çin'de en önemli 11 patates çeşidini in vitro koşullarda MS ortamında farklı PEG 8000 konsantrasyonlarının (\%5, $\% 10, \% 15$ ve \%20) büyüme ve gelişmeye etkilerini araştırdıkları çalışmalarında in vitro koşullarda tüm patates bitkileri PEG seviyesi artıkça farklı düzeylerde kuraklık stresi göstermişlerdir. \%15 PEG'te 11 çeşitte büyük farklılıklar elde edilmiş ve tüm büyüme göstergeleri kontrole göre daha düşük değerler oluşturmuştur. Patateste in vitro koşullarda \%15 PEG konsantrasyonu kuraklığı test etmek için en üst konsantrasyon seviyesi olarak belirlenmiştir. Tabori et al. (2017) in vitro koşullarda yaptıkları çalışmada bazı ıslah hatlarında PEG 6000'in üç farklı konsantrasyonunu (\%2.5, \%5 ve \%7.5) kullanmışlar ve çalışmada bazı ileri hatlarda kuraklık toleransı belirlemişlerdir. Çalışma sonucunda PEG-6000 \%7.5'lik konsantrasyonu in vitro patates kuraklık çalışmalarında yeterli bir seviye olduğunu belirtmişlerdir. 
Quayyum and Schoaib (2013), Nistor et al. (2014) ve Deng et al. (2014)'nın araştırma sonuçlarına benzer şekilde araştırmada kullandığımız kontrol (MSO) ortamı, PEG içeren ortamlara göre daha yüksek değerler vermiştir. Her 3 araştırmada da çeşitler PEG'in farklı konsantrasyonlarında farklı şekilde tolerans göstermişlerdir. Genel olarak PEG konsantrasyonu artışı bitki geliş̧imini olumsuz etkilemiştir. Yaptığımız çalışmada Milva çeşidi, 13-80-44, 12-55-07, 22-99-33 ve 12-69-39 ileri hatları kuraklık stresine karşı daha yüksek seviyede tolerans göstermişler, büyüme ve gelişme seviyeleri Saline çeşidi ve diğer hatlara göre daha üst seviyede gerçekleşmiştir. Bitki kuraklık toleransı ile çoğunlukla morfolojik özellikler arasında bir ilişki olduğu belirtilmiştir (Tuberosa, 2012). Patateste kuraklık toleransı artıkça patates çeşitlerinin güçlü bitki yapısı ve daha büyük yeşil aksam geliştirdiği (Schittenhelm et al. 2006) ve geçci patates genotiplerinin daha büyük ve daha derin kök sistemleri ile kuraklığa daha fazla tolerans gösterdikleri belirlenmiştir (Iwama, 2008; Soltys-Kalina et al. 2016). Araştırmada benzer şekilde orta erkenci (12-55-07) ve orta erkenci-geçci ileri hatlarda (13-80-44 ve 22-99-33) in vitro koşullarda kuraklık toleransı daha yüksek bulunmuştur.

\section{KAYNAKLAR}

Albiski, F., S. Najla R. Sanoubar N. Alkabani and R. Murshed. 2013. In vitro screening of potato lines for drought tolerance. Physiology and Molecular Biology of Plants, 18(4): 315-321.

Bhattarai, P. 2017. Effects of plant growth regulators on growth and yield of pre-basic seed potato production under glasshouse condition. SAARC Journal of Agriculturae, 15(1): 149-160.

Charloq, E., Panjaitan and B.A. Sirait. 2012. Study of early screening of potato (Solanum tuberosum L.) as a result of drought stress (in vitro). Proceedings of the 2 nd Annual International Conference Syiah Kuala University \& The 8th IMT-GT Uninet Biosciences Conference Banda Aceh. 2(1): 403-405.

Dalla Costa, L., G. Delle Vedove G. Gianquintoi R. Giovanardi and A. Peressotti. 1997. Yield, water use efficiency and nitrogen uptake in potato: influence of drought stress. Potato Research, 40:19-34.

Deblonde, P.M.K and J.F. Ledent. 2001. Effects of moderate drought conditions on green leaf number, stem height, leaf length and tuber yield of potato cultivars. European Journal of Agronomy, 14: 31-41.

Deng, Z., J.F. Xu G.G. Duan J. Liu C.S. Bian W.F. Pand and L.P. Jin. 2014. Effect on growth indicators of 11 potato cultivars in vitro under PEG-8000 stress. Acta Agriculturae Boreali-Sinica, 29 (5): 99-106.

Eiasu, B.K., P. Soundy and P.S. Hammes. 2007. Response of potato (Solanum tuberosum) tuber yield components to gelpolymer soil amendments and irrigation regimes, New Zeland Journal of Crop Horticulture, 35: 25-31.

Ekanayake, I.J. and D.J. Midmore. 1992. Genotypic variation for root pulling resistance in potato and its relationship with yield under water-deficit stress. Euphytica, 61:43-53.

\section{SONUÇ}

Araştırma sonucuna göre ticari çeşitlerden Milva çeşidi Saline çeşidine göre in vitro koşullarda PEG kaynaklı suni kuraklık stresine daha tolerant olarak belirlenmiştir. Araştırmada üstün agronomik, yumru ve verim özelliklerine sahip 6 ileri hat kullanılmıştır. Hatlar arasında $13-80-44$ ve 22-99-33 hatları in vitro koşullarda kuraklık toleransı yüksek patates hatları olarak belirlenmiştir. In vito koşullarda PEG 6000 kullanılarak kuraklık toleransını belirlemenin en büyük avantajı fazla sayıda ıslah hattında ya da çeşitte kısa sürede kuraklık tolerans ya da dayanıklılığının belirlenmesine olanak sağlayabilmesidir. In vitro koşullarda kuraklık toleransı yüksek hatlar olarak belirlenen bu hatlardan elde edilecek mini yumru ya da tohumluk yumruların normal tarla koşullarında denemelere alınarak kuraklığa tepkileri belirlendikten sonra kuraklık toleransı yüksek ticari çeşit adayı olarak değerlendirilmesi gerekmektedir. In vitro koşullarda \%15 PEG konsantrasyonunun kuraklığı test etmek için üst sınır olarak kullanılabileceği ve daha yüksek PEG konsantrasyonlarının bitkilerde önemli seviyede büyüme ve gelişme geriliğine ve daha ilerisinde ise bitki ölümlerine neden olabileceği sonucuna varılmıştır.

Freed, R., S.P. Einensmith S. Guetz D. Reicosky V.W. Smail and P. Wolberg. 1989. User's Guide to MSTAT-C Analysis of Agronomic Research Experiments, Michigan State University USA.

Gopal, J. 2001. In vitro and in vivo genetic parameters and character associations in potato. Euphytica, 118: 145-151.

Gopal, J. and K. Iwama. 2007. In vitro screening of potato against water-stress mediated through sorbitol and polyethylene glycol. Plant Cell Reports, 26: 693-700.

Hussain, M., M.A. Malik M. Farooq M.Y. Ashraf and M.A. Cheema. 2008. Improving drought tolerance by exogenous application of glycine-betaine and salicylic acid in sunflower. Journal of Agronomy and Crop Science, 194:193-199

Iwama, K. and J. Yamaguchi. 2006. Abiotic stresses, in: J. Gopal, S.M. Paul Khurana (Eds.), Handbook of Potato Production Improvement and Post Harvest Management, Food Product Press, New York. pp. 231-278.

Iwama, K. 2008. Physiology of the potato: new insights into root system and repercussions for crop management. Potato Research, 51: 333-353.

Jacomini, E., A. Bertani and Mapelli. 1988. Accumulation of polyethylene glycol 6000 and its effects on water content and carbohydrate level in water-stressed tomato plant, Canadian Journal of Botany, 66: 970-973.

Kaya, M.D., G. Okçu M. Atak Y. Çıkılı and Ö. Kolsarıcı. 2006. Seed treatments to overcome salt and drought stress during germination in sunflower (Helianthus annuus L.). European Journal of Agronomy, 24: 291-295. 
Kızıloğlu, F.M., Ü. Sahin T. Tunç and S. Diler. 2006. The effect of deficit irrigation on potato evapotranspiration and tuber yield under cool season and semiarid climatic condition. Journal of Agronomy. 5: 284-288.

Kumar, S., R. Asrey and G. Mandal. 2007. Effect of differential irrigation regimes on potato (Solanum tuberosum) yield and postharvest attributes, Indian Journal of Agricultural Science, 77: 366 368.

Lahlou, O., S. Ouattar and J.F. Ledent. 2003. The effect of drought and cultivar on growth parameters, yield and yield components of potato. Agronomie, 23: 257-268.

Manoj, K. and D. Uday. 2007. Gradient in vitro testing of tomato (Solanum lycopersicum) genotypes by inducing water deficit: a new approach to screen germplasm for drought tolerance. Asian Journal of Plant Science, 6: 934-940.

Mengü-Pamuk, G., S. Anaç ve E. Özçakal. 2011. Kuraklık yönetim stratejileri. Ege Üniversitesi Ziraat Fakültesi Dergisi, 48(2): 175-181.

Monneveux, P., D.A. Ramíreza and M.T. Pino. 2013. Drought tolerance in potato $(S$. tuberosum L.) Can we learn from drought tolerance research in cereals? Plant Science, 205-206: 76-86.

Murashige, T. and F. Skoog. 1962. A revised medium for rapid growth and bioassay with tobacco cultures. Physiol. Plant. 5: 473-497.

Nistor, A., M. Cioloca N. Chiru and M. Popa. 2014. In vitro response to drought tolerance for different potato varieties. Analele Universităţii din Oradea, Fascicula Protecţia Mediului, 13: 257-262.

Qayyum, M. and K. Shoaib. 2013. Selection of potato (Solanum tuberosum L. cv. Cardinal) plantlets tolerant to in vitro salt and drought stress. Pakistan Journal of Biochemistry and Molecular Biology, 46(1): 37-41.

Pino, M.T., A. Ávila A. Molina Z. Jeknic and T.H.H. Chen. 2013. Enhanced in vitro drought tolerance of Solanum tuberosum and Solanum commersonii plants overexpressing the ScCBF1 gene. Cien. Inv. Agr., 40(1):171-184.
Renault, D. and W.W. Wallender. 2000. Nutritional water productivity and diets: from "crop per drop" towards "nutrition per drop", Agricultural Water Management, 45: 275-296.

Schafleitner, R., R. Gutiérrez R. Espino A. Gaudin J. Pérez M. Martínez A. Domínguez L. Tincopa C. Alvarado G. Numberto and M. Bonierbale. 2007. Field screening for variation of drought tolerance in Solanum tuberosum L. by agronomical, physiological and genetic analysis. Potato Research, 50: 71-85.

Schittenhelm, S., H. Sourell and F. Lopmeierc. 2006. Drought resistance of potato cultivars with contrasting canopy architecture. European Journal of Agronomy, 24:193-202.

Soltys-Kalina, D., J. Plich, D. Strzelczyk-Żyta, J. Śliwka and W. Marczewski. 2016. The effect of drought stress on the leaf relative water content and tuber yield of a half-sib family of 'Katahdin' derived potato cultivars. Breeding Science, 66: 328-331.

Stark, J.C., S.L. Love, B.A. King, J.M. Marshall, W.H. Bohl and T. Salaiz. 2013. Potato cultivar response to seasonal drought patterns. American Journal of Potato Research, 90: 207-216.

Tábori, K.M., A. Hanász N.M. Drienyovszki L. Zsombik and J. Dobránszki. 2017. Study of osmotic stress tolerance of potato breeding clones in vitro shoot cultures. $20^{\text {th }}$ EAPR Triennial Conference. 9-14 July 2017, Paris, France, p.98.

Tuberosa, R. 2012. Phenotyping for drought tolerance of crops in the genomics era. Front. Physiol., 3: 347.

Weisz, R., K. Kaminski and Z. Smilowitz. 1994. Water deficit effects on potato leaf growth and transpiration: utilizing fraction extractable soil water for comparison with other crops. American Journal of Potato Research, 71: 829-840.

Yaniv, Z. and E. Werker. 1983. Absorption and secretion of polyethylene glycol by Solanaceous plants, Journal of Experimental Botany, 34: 1577-1584.

Yuan, B.Z., S. Nishiyama and Y. Kang. 2003. Effects of different irrigation regimes on the growth and yield of drip-irrigated potato. Agricultural Water Management, 63: 153-167. 